\title{
Impact of educational intervention regarding anaemia and its preventive measures among pregnant women: an interventional study
}

\author{
Pankajkumar B. Nimbalkar', Jaldhara N. Patel ${ }^{2 *}$, Nilesh Thakor ${ }^{3}$, Mansi Patni ${ }^{4}$
}

\author{
${ }^{1}$ Department of Obstetrics and Gynecology, GMERS Medical College, Dharpur-Patan, Gujarat, India \\ ${ }^{2}$ Department of Obstetrics and Gynecology, ${ }^{3}$ Department of Community Medicine, GMERS Medical College, \\ Gandhinagar, Gujarat, India \\ ${ }^{4}$ Department of Foods and Nutrition, The Maharaja University of Baroda, Vadodara, Gujarat, India
}

Received: 07 November 2017

Accepted: 11 November 2017

\section{*Correspondence:}

Dr. Jaldhara N. Patel,

E-mail: researchforbetterhealth@gmail.com

Copyright: (C) the author(s), publisher and licensee Medip Academy. This is an open-access article distributed under the terms of the Creative Commons Attribution Non-Commercial License, which permits unrestricted non-commercial use, distribution, and reproduction in any medium, provided the original work is properly cited.

\section{ABSTRACT}

Background: Iron deficiency anaemia (IDA) is the most common nutritional deficiency in pregnancy and major contributory factor to maternal morbidity and mortality. Objective of present study was to assess knowledge of pregnant women regarding anaemia and its preventive measures before and after educational interventional training.

Methods: The present study was an interventional study undertaken in purposively selected pregnant women attending the out patient Department of Obstetrics and Gynecology Department of GMERS Medical College, Gandhinagar During the month of October 2017. Total 100 pregnant women were included after written informed consent. Baseline knowledge of pregnant women regarding anaemia and its preventive measures was assessed by predesigned, pre-tested and semi structured questionnaire. Single educational interventional training for 45 minutes was given to selected pregnant women. Post-intervention knowledge of pregnant women for the same was assessed after training. Thus, collected data was analyzed /using Epi info 7.

Results: Baseline knowledge of the pregnant women regarding causes, signs and symptoms of anemia and dietary sources of iron was $21 \%, 23 \%$ and $40 \%$ respectively which was significantly increased to $64 \%$, $66 \%$ and $72 \%$ respectively after the intervention. Baseline knowledge of the pregnant women regarding factors which inhibit and increase iron absorption was $25 \%$ and $4 \%$ respectively which was significantly increased to $55 \%$ and $41 \%$ respectively after the intervention. Baseline knowledge of the pregnant women regarding treatment of anaemia was $30 \%$ which was significantly increased to $79 \%$ after the intervention.

Conclusions: There was significant improvement in the knowledge regarding anaemia and its preventive measures among pregnant women after our single educational session.

Keywords: Anaemia, Knowledge, Iron, Pregnant women, Prevalence

\section{INTRODUCTION}

The most common nutritional deficiency in pregnancy is Iron deficiency anaemia (IDA). World Health Organization defined anaemia as haemoglobin less than $11 \mathrm{gm} / \mathrm{dl}$ and a haematocrit of less than 0.33 . The iron reserve was partially or completely depleted during beginning of the pregnancy in most of the women. Thus, the severity of the anaemia is inversely related to the amount of iron reserves. ${ }^{1,2}$

Anaemia is a major contributory factor to maternal morbidity and mortality in many underdeveloped and developing countries. According to WHO, prevalence of anemia in developed and developing countries in pregnant women are 14 percent in developed and 51 
percent in developing countries and $65-75$ percent in India. ${ }^{3}$ Prevalence of anemia in adolescent girls, pregnant women and in lactating mother is higher in India as compared to other developing countries. As per National Family Health Survey- 4 (NFHS-4) prevalence of Iron deficiency anaemia (IDA) in pregnant women is $50.3 \%$ in India and $51.3 \%$ in Gujarat. ${ }^{4,5}$

Adequate maternal nutrition knowledge and dietary practice before and during pregnancy is necessary to ensure positive pregnancy outcomes. According to Nasah and Drouin, Pregnancy and delivery exposes the Cameroonian mother to $2 \%$ risk of death during their reproductive life, with $43.3 \%$ of maternal death resulting from haemorrhage, $8.3 \%$ from pre-eclampsia and $4.2 \%$ from placenta abruption, all of which are nutrition related. ${ }^{6}$ It was shown that, nutrition knowledge was predictive of change in dietary habits and sensitization improved their quality of food intake. ${ }^{7}$

Knowledge of mothers has an important role in the maintenance of nutritional status of the children. Adequate knowledge regarding various aspects of feeding practices during pregnancy and during infancy is very essential especially among females as they are going to influence the feeding practices of this vulnerable group. Mothers educational level, position, health and nutritional status is central to the quality of life and is a key ingredient of her child's health, nutritional status, behavioral and other aspects of child welfare in developing countries. With this background in mind, the present study was undertaken to know impact of educational intervention regarding anaemia and its preventive measures before and after training among pregnant women.

\section{METHODS}

The present study was an interventional study undertaken in purposively selected pregnant women attending the out patient Department of Obstetrics and Gynecology Department of GMERS Medical College, Gandhinagar During the month of October 2017. Total 100 Pregnant women were included after written informed consent. Baseline knowledge of pregnant women regarding anaemia and its preventive measures was assessed by predesigned, pre-tested and semi structured questionnaire. Questionnaire was converted in vernacular language for assessment.

Single educational interventional training for 45 minutes was given to selected adolescent girls with lecture with power point presentation, charts, demonstration and discussion. Post- intervention knowledge of students for the same was assessed after training by same questionnaire. Pre and post training assessment was done by scoring method and also mean, standard deviation, Wilcoxon sign rank test were applied. Thus, collected data was analyzed using Epi Info 7.

\section{RESULTS}

Age range of pregnant women was 21-34 years. Mean age of the pregnant women was $26.6 \pm 0.9$ years. All women belonged to social class 3 . All women are literate. Out of 100, 32 women were graduate, 52 women had completed higher secondary schooling and 16 women had completed primary schooling. Out of 100 women, 23 women were working while 77 women were housewife.

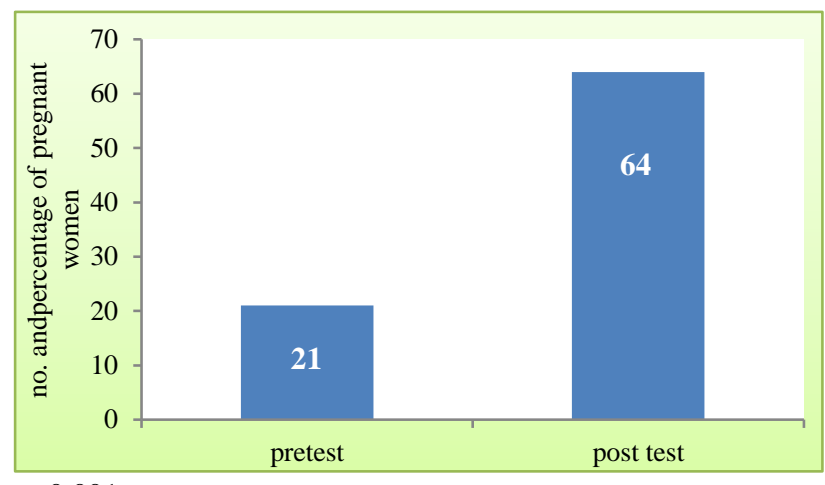

$\mathrm{p}<0.001$

Figure 1: Distribution of pregnant women according to knowledge of causes of anaemia before and after training.

Out of total, only $21 \%$ pregnant women had baseline knowledge regarding causes of anaemia. The same knowledge has been increased to $64 \%$ after the intervention and the increase in the knowledge was very significant $(\mathrm{p}<0.001)$ (Figure 1).

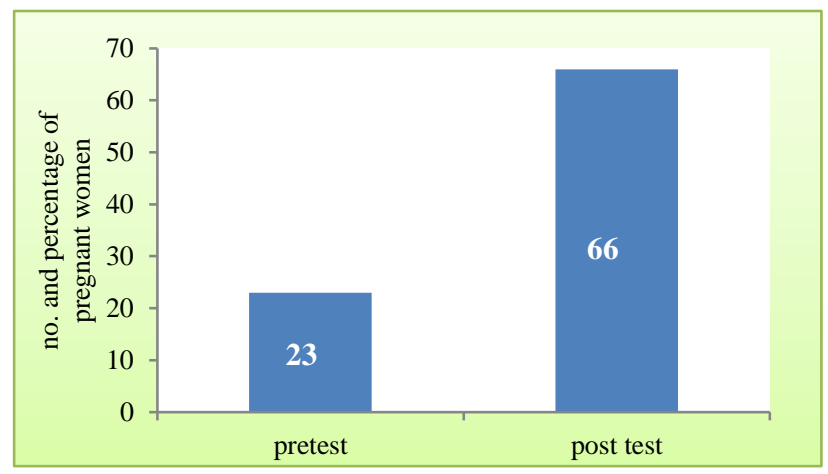

$\mathrm{p}<0.001$

Figure 2: Distribution of pregnant women according to knowledge regarding signs and symptoms of anaemia before and after training.

Out of total, only $23 \%$ pregnant women had baseline knowledge regarding signs and symptoms of anaemia. The same knowledge has been increased to $66 \%$ after the intervention and the increase in the knowledge was very significant $(\mathrm{p}<0.001)$ (Figure 2).

Out of total, only $40 \%$ pregnant women had baseline knowledge regarding dietary sources of iron. The same knowledge has been increased to $72 \%$ after the 
intervention and the increase in the knowledge was very significant $(\mathrm{p}<0.001)$ (Figure 3$)$.

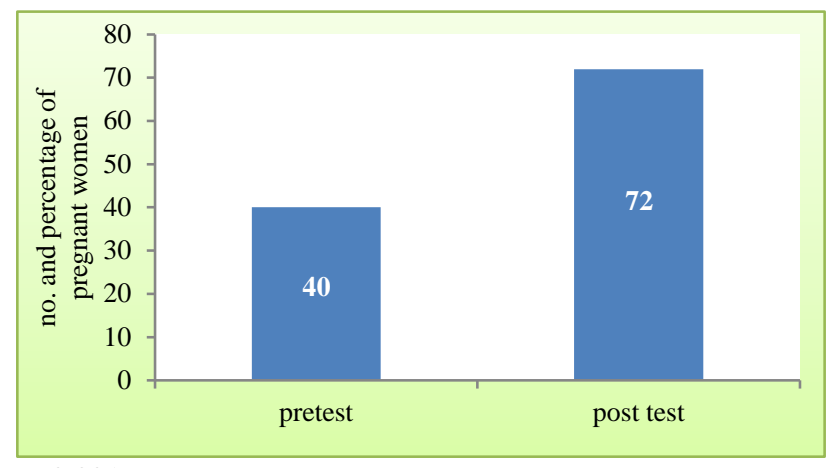

$\mathrm{p}<0.001$

Figure 3: Distribution of pregnant women according to knowledge of sources of iron before and after training.

Out of total, only $25 \%$ pregnant women had baseline knowledge regarding factors which inhibit the absorption of iron. The same knowledge has been increased to $55 \%$ after the intervention and the increase in the knowledge was very significant $(\mathrm{p}<0.001)$ (Figure 4$)$.

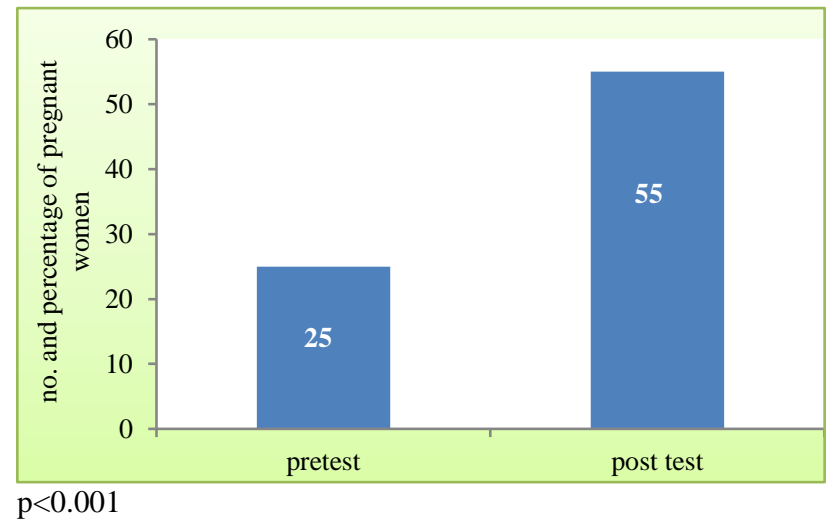

Figure 4: Distribution of pregnant women according to knowledge of factors which inhibit absorption of iron before and after training.

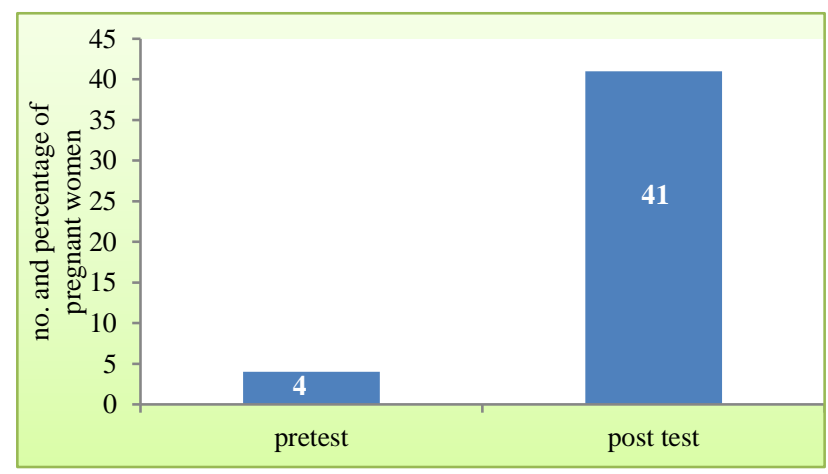

$\mathrm{p}<0.001$

Figure 5: Distribution of pregnant women according to knowledge of factors which increase absorption of iron before and after training.
Out of total, only $4 \%$ pregnant women had baseline knowledge regarding factors which increase the absorption of iron. The same knowledge has been increased to $41 \%$ after the intervention and the increase in the knowledge was very significant $(\mathrm{p}<0.001)$ (Figure $5)$.

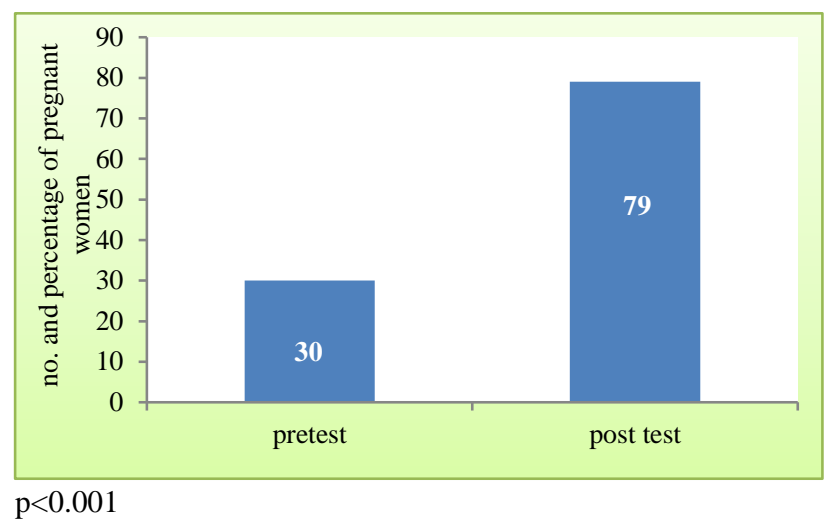

Figure 6: Distribution of pregnant women according to knowledge of treatment of anaemia before and after training.

Out of total, only $30 \%$ pregnant women had baseline knowledge regarding treatment of anaemia. The same knowledge has been increased to $79 \%$ after the intervention and the increase in the knowledge was very significant $(\mathrm{p}<0.001)$ (Figure 6).

\section{DISCUSSION}

Nutrition during preconception as well as throughout pregnancy has a major impact on the outcome of pregnancy. Women who eat well and avoid known risks tend to have fewer complications during pregnancy labour and more likely to deliver live normal healthier babies. On the contrary women who are malnourished before and during pregnancy are more likely to experience adverse pregnancy outcomes. Before pregnancy the woman needs nutrients for growth and maintenance of her body. Good nutrition keeps her healthy.

During pregnancy additional requirement for all nutrients occurs to enable the foetus to grow normally in the uterus. However, nutritionists, prenatal care providers and public policymakers all accept that it is the quality of the diet, not its quantity that is most important. Thus, it is argued that, pregnant women who eat empty calorie foods may gain adequate (or even excessive) amounts of weight during pregnancy but are nevertheless at nutritional risk for adverse pregnancy outcomes

In present study mean age of the pregnant women was 26.6 \pm 0.9 years. Baseline knowledge of the pregnant women regarding causes of anaemia was $21 \%$ which was significantly increased to $64 \%$ after the intervention. 
Baseline knowledge of the pregnant women regarding signs and symptoms of anaemia was $23 \%$ which was significantly increased to $66 \%$ after the intervention. Baseline knowledge of the pregnant women regarding dietary sources of iron was $40 \%$ which was significantly increased to $72 \%$ after the intervention. Baseline knowledge of the pregnant women regarding factors which inhibit the absorption of iron was $25 \%$ which was significantly increased to $55 \%$ after the intervention.

Baseline knowledge of the pregnant women regarding factors which increase the absorption of iron was $4 \%$ which was significantly increased to $41 \%$ after the intervention. Baseline knowledge of the pregnant women regarding treatment of anaemia was $30 \%$ which was significantly increased to $79 \%$ after the intervention.

Present finding that a majority of the mothers had great awareness of the importance of good maternal nutrition before and during pregnancy and balanced diet is contrary to that revealed in a study by Daba et al in Ethiopia where most $(74.0 \%)$ of the respondents did not know the main food groups of the balance diet and more than half $(57.8 \%)$ of them did not even know the meaning of food. ${ }^{8}$ Also, the results of another study reported from America at El-Menshawy Hospital showed that about half of the women did not have enough knowledge regarding the meaning, the importance, and the constituents of a well balanced diet. ${ }^{9}$

The high level of nutrition knowledge demonstrated in our study maybe due to high educational level of the respondents as more than three quarters $(77 \%)$ of them had at least secondary education; contrary to the Ethiopian study where $65.4 \%$ of the mothers were non scholarised and $25.1 \%$ of them had primary education. Despite the high literacy level of respondents, some confusion and ignorance existed as regards maternal knowledge of adequate nutrition practices during pregnancy and identification of potential harmful food items in pregnancy. This finding is in consonant with that of Yassin et al in Alexandria, Egypt where $61.7 \%$ of the respondents were found to have poor knowledge of dietary practices in pregnancy. ${ }^{10}$ However a contrary finding was reported by Zeng on the knowledge of nutrition and related dietary behaviours among pregnant women, where $74.9 \%$ of the respondents showed good knowledge of dietary practices during pregnancy. ${ }^{11}$

In a similar way, Kever et al in the study of knowledge and attitude of pregnant women towards dietary practices in Yerwa clinic, Maiduguri metropolitan council; Borno state of Nigeria, discovered that $65.31 \%$ of the respondents showed a high knowledge about dietary practices during pregnancy despite high level of illiteracy among the respondents. ${ }^{12}$ The probable reason for the discrepancy may be differences in socio-cultural values of the study populations with respect to food and exposure to nutrition information during pregnancy.
However, study done in single college of Gandhinagar city limits us to generalize the results. There is definitely a need for well-planned, large-scale studies using standardized methodologies to evaluate dietary practices including prevention of anaemia in pregnancy among pregnant women.

\section{CONCLUSION}

There was significant improvement in the knowledge regarding anaemia and its preventive measures among pregnant women after our single educational session. Such education interventions are to be done on a regular basis in outpatient department to improve their knowledge and to encourage them to adopt healthy lifestyles which prevents anaemia and other micronutrient deficiencies during and after pregnancy.

\section{Funding: No funding sources \\ Conflict of interest: None declared}

Ethical approval: The study was approved by the Institutional Ethics Committee

\section{REFERENCES}

1. Breymann C. Iron deficiency and anemia in pregnancy: Modern aspects of diagnosis and therapy. Blood Cells Mol Dis. 2002;29:506-16.

2. Khan MM. Effects of maternal anemia on fetal parameters. J Ayub Med Coll Abbottabad. 2001;13:38-41.

3. Thakor N, Bhagora S, Asari U, Kharadi A, pandor J, prajapati D. Effect of intravenous iron sucrose therapy for moderate-to-severe anemia in pregnancy: a longitudinal study. Int J Med Sci Public Health. 2015;4:11-14.

4. International institute for population sciences (IIPS) and macro International. 2016. National family health survey (NFHS-4), India, 2015-16: India. Mumbai: IIPS Available at http://rchiips.org/NFHS/pdf/NFHS4/India.pdf. Accessed on 15 October 2017

5. International institute for population sciences (IIPS) and macro International. 2016. National family health survey (NFHS-4), India, 2015-16: Gujarat. Mumbai: IIPS. Available at http://rchiips.org/NFHS/pdf/NFHS4/GJ_FactSheet.p df. Accessed on 15 October 2015

6. Nasah TB, Drouin P. Major factors affecting maternal and child health. Care of the mother in the tropics, CEPER. 1982:9-15

7. O'Brien G, Davies M. Nutrition knowledge and body mass index. Health Educ Res. 2007;22:571-5.

8. Daba G, Beyene F, Fekadu H, Garoma W. Assessment of knowledge of pregnant mothers on maternal nutrition and associated factors in Guto Gida Woreda, East Wollega Zone, Ethiopia. J Nutr Food Sci. 2013;3:235. 
9. Latifa MF, Manal HA, Nihal SS. Nutritional awareness of women during pregnancy. J American Sci. 2012;8(7):494-502.

10. Yassin SA, Sobhy SI, Ebrahim W. Factors affecting dietary practice among adolescent pregnant women in Alexandria. J Egypt Public Health Assoc. 2004;34:179-196.

11. Zeng N. Knowledge of nutrition and related dietary behaviours among floating women under pregnancy. American J Clin Nutr. 2005;79(1):17-21.

12. Kever RT, Martins SD, Lola N, Dathini H, Habu H, Fatima AA, Sambo BD. Knowledge and attitude of pregnant Women towards dietary practices in Yerwa Clinic, Maiduguri Metropolitan Council; Borno State. JRNM. 2015;4(1):12- 19.

Cite this article as: Nimbalkar PB, Patel JN, Thakor N, Patni M. Impact of educational intervention regarding anaemia and its preventive measures among pregnant women: an interventional study. Int J Reprod Contracept Obstet Gynecol 2017;6:531721. 